\title{
Study on the Cultivation Models of "Grey Collar" Talents in Vocational Colleges
}

\author{
Kai Zhu", Peng Sun ${ }^{\#}$ and Xin Zhao* \\ Department of Biological and Chemical Engineering, Chongqing University of Education, Chongqing 400067, China \\ foods@live.cn
}

\begin{abstract}
With the development of economy and the needs of society, more and more attention are paid to "gray collar" talents, who have strong capabilities in theory and practice. Cultivating "gray collar" talents becomes an important issue that higher vocational colleges should be aware of. This study is mean to explore the training mode of "gray collar" talents for higher vocational colleges by defining the cultivation orientation and approaches. Only by converting the tradition training mode, can higher vocational colleges bring up more and more qualified "gray collar" talents to boost the rapid and sound development in this field.
\end{abstract}

Index Terms - vocational colleges, gray collar talents, training mode, research

\section{Introduction}

Originating from the USA, "Grey collar" has been a brand-new occupation concept that ignites people's reflection on attitude towards employment, driving the whole society to explore the "grey collar" occupation. Actually, the grey collar refers to talents with high knowledge level, strong innovation ability and proficient professional skills. Compared to the white collar and the blue collar, the grey collar is equipped with decent manipulative ability as well as ample theory knowledge.

The improvement and change of national industrial structure result in the demand for grey collar talents. An increasing amount of labor force is engaged in the second and third industry due to the change of national industrial structure. With the growing content of technology in production as well as service and the increasing complexity of labor, there are many special posts in manufacture and service industry. These posts require labors to be equipped with both professional theory knowledge and strong manipulative ability. From the perspectives of industry and nature of jobs, the grey collar can also be considered to be skilled staffs who work on the front line to do sophisticated operation, be responsible for designing as well as production management and provide creative service in service industry. They are qualified to work as not only operators in crucial production processes but also the organizers in the whole production [1]. In some industries, grey collar talents possess great ability to make technological innovations, remain public relations and make improvements to projects. For instance, they are demanded in industries including IT programs, multimedia making, NC programming, video processing and motion capture techniques.
The ability of practice and thought is the typical feature of the grey collar. Having academic certificate and senior vocational qualification certificate in hand, the grey collar talents possess proficient skills and work on the front line. Their salary is 3-5 times of that of the white collar or blue collar talents. Being equipped with more knowledge and more professional skills than the blue collar talents, they would become pilot professional talents and grey collar jobs would be sought-after ones in the future. For the moment, vocational colleges have been among the main bases for the cultivation of grey collar talents. There is no mature experience to be used for reference in China. It mainly takes examples by the foreign vocational cultivation methods. The cultivation and development of talents with sophisticated skills is in a backward stage and lag behind the fast developing economy. Thus, it is urgent to promote the pace of cultivation [2]. It takes continuous practice, innovation and pedagogical reform for vocational colleges to cultivate applied talents with great prowess for the society. As the key factors to create effective and fair results, education and talent cultivation guarantee the prosperity and stability of the society and economy [3].

\section{Cultivation Direction of the grey Collar Talents}

\section{A. Aiming at Cultivating Key Competence}

Steps of traditional talent training model are as follows: teachers teach in the class; students take notes; a final examination is arranged to check the students. Such training model is nothing but knowledge inoculation and knowledge cannot be transferred into practical ability, especially into key competence. On the contrary, with practicalness as the basis, the grey- collar -talent training model attaches more importance to the combination of theoretical knowledge and practical operation and the transformation from knowledge to practical ability or key competence.

Key competence is also called core competence. Having no direct relation with pure professional vocational skills and professional knowledge, it is beyond the scope of vocational skills and knowledge. Being transferable and involved with many vocations, it can make labors adapt to new environment where the skills and knowledge of labors are not suitable for the new production processes and new work organization. The fierce competition for jobs depreciates the value of skills endowed by vocational education. However, undoubtedly, receiving ability training is the unique way to master skills

\footnotetext{
${ }^{*}$ Corresponding author: Prof. Xin Zhao, ${ }^{\#}$ these authors contributed equally to this work
} 
related to work [4]. Therefore, the cultivation of key competence is mainly done during the production process. It includes the learning ability and comprehensive development ability to discover, think over, and solve problems. Hammering away at the cultivation of the key competence of students enables students to adapt to the change of the society and vocations, thus equipping them with ability to survive in the society.

\section{B. Method: Step by step, echelon cultivation}

The basis for the cultivation of the grey collar talents is the demand of the enterprises. Without definite demand of the enterprises, talent cultivation is aimless. The demands of enterprises are mainly from aspects as follows: first, reformation of production techniques. With the change of technologies, more and more technological fruits turn into productivity and enterprises are faced with challenges of new products, new procedures, new crafts and new equipment at any time. Thus, effective responses are in urgent need. Enterprises need to adapt to new talents [5]. Second, demand resulting from personnel change. It's common for enterprises to have personnel change. Staffs on crucial posts sometimes come and go. Enterprises have to choose new talents to fill the possible vacancy to avert troubles. Third, demand resulting from innovation. Innovation is the momentum that an enterprise can remain vitality. An enterprise would decline in the competitive society without innovative ability.

The step-by-step and echelon cultivation methods serve the enterprises. Making progresses step by step includes the increase of knowledge, enhancement of ability and the improvement to skill proficiency. There is advance and retreat. Enterprises can select grey collar talents suitable for their development with corresponding talent-differentiation mechanism to realize gradual elimination reasonably.

\section{The Methods for Grey Collar Talent Cultivation}

\section{A. Restructure the curricular system with Occupation as the orientation}

With the development of market economy, the proportion of talent demand is changing. Vocational colleges have to cultivate grey collar talents according to the demand of the market and adjust their majors and curricular system. The advancement of technology makes different vocations and disciplines integrate and penetrate mutually. Some traditional vocations disappear and some new ones come into being, which calls for graduates to be equipped with strong adaptability to fit new vocations, posts and environment. However, students are not satisfied with what they have learned in colleges including the teaching methods and its quality. They lack ability to cope with jobs and the society [6]. Graduates with monotonic knowledge structure would fall into disuse in the society. Therefore, apart from knowing everything of something, students have to know all things of everything. Majors and curriculums are supposed to adapt to social demands. Main courses are equipped with flexibility with more relations with the society.
On one hand, vocational colleges can encourage enterprises take an active part in the setup of majors. New majors can be set up according to the need of the society; on the other hand, vocational colleges can broaden knowledge of students by means of arranging more selective courses to realize the transformation from monotonic -skill training to comprehensive- skill cultivation [7].

\section{B. Emphasizing the combination of produce-learn-research}

The nature of the combination of "produce-learnresearch" is that vocational colleges cultivate talents together with enterprises. As a specific education model, it aims to equip students with both theoretical knowledge and vocational skill training. The cultivation model of "produce-learnresearch" would guarantee the application of grey collar talents. Parallel with others in theory, talents cultivated with such model are superior in solving practical problems. In this model, colleges are supposed to provide interns for enterprises while enterprises would provide practical training and training sites.

Colleges can also send teachers to enterprises regularly to do practice to improve their ability or invite professional technicians of enterprises to provide guides to students [8]. In this cultivation model, vocational colleges can build research institutes or practice centers together with enterprises, thus enhancing the construction of majors and curriculum. Furthermore, research fruits of colleges can be transformed into productivity directly to facilitate the development of enterprises in turn. Apart from satisfying the demand of talents of enterprises, vocational colleges have to attract the technological support and funding support from enterprises to build stable "produce-learn-research" cooperation with enterprises. Only when enterprises recognize the importance of practical talents to its development can they provide human, physical and financial resources to cooperate with colleges. "produce-learn-research" model in real sense can be realized when enterprises regard the cooperation with colleges as the boost of their development to build practical training centers and offer opportunities for students to do practice on the front line.

Through the combination of "produce, learn, research" with enterprises, vocational colleges can learn about the change of market and demand of enterprises. On the other hand, as enterprises participating in the cultivation of students, they have some knowledge of the ability of students, which can increase their confidence in graduates. Such cooperation is in favor of cultivating more grey collar talents and creating more job opportunities.

\section{Adopting "make to order" cultivation model}

Vocational colleges have to be occupation-oriented. They would have high employment rate when their graduates are recognized by enterprises [9]. Therefore, market investigations and negotiation with enterprises are supposed to be made before recruiting. The vocational colleges sign contacts with enterprises and recruit students according to the demand of enterprises. The two sides make the cultivation schedule of 
grey collar talents together. Pertinent to specific posts, such schedule can shorten the adaptation time of students. In the whole cultivation schedule, vocational colleges provide theoretical background for students while enterprises provide practice opportunities. Students would work in specific posts for sometime and then be employed as a full member. Such cultivation method guarantees the employment of students since their enrollment. Make to order cultivation model serve to provide grey collar talents suitable for the development and environment of enterprises.

\section{D. "Double certificates" training mode establishing}

With the development of economy, enterprises put more importance on qualification certificates which are more suitable for the demand of market economy compared to diploma certificates. The government promotes employment access system in some industries and qualification certificates of all walks of life vigorously, which would make the focus shift from diploma-orientation to qualification certificateorientation. More attention should be paid to qualification certificates instead of the education background to check the ability of the grey collar talents. Diploma is nothing but a testimonial to one's culture base. Pure theory should be understated by means of highlighting qualification tests.

The quality of human resources, innovation ability and proficiency of skills determine the development of knowledge economy. Important as diploma is, it cannot reflect the specific ability of a student directly and can never equal to the practical skills of a student. For instance, the salary of many welleducated people who are qualified for works requiring no professional skills is much lower than that of people with professional skills [10]. It's because that they have no specific professional skills. However, vocational colleges cannot neglect the importance of diploma. After all, the skill level of a person is in direct proportion to his or her learning ability.

Double certificates regulation means graduates from vocational colleges have both diploma certificates and vocational qualification certificates. Attaching equal importance to the two certificates can cultivate grey collar talents with both theoretical knowledge and vocational operation skills, which conforms to features of the grey collar talents who are equipped with both sound theoretical knowledge and strong manipulative ability. They can adapt to features of the posts as soon as possible. With the increase of technology in production process, increasing number of grey collar talents would be active in crucial posts on the front line. Candidates need to have both diploma and corresponding professional skills to get a crucial post. Talents with both working experience and senior or intermediate vocational qualifications are the most sought-after ones.

\section{Summary}

To conclude, it has a long way to go to cope with the cultivation of grey collar talents and enhancement of the ability of grey collar talents. It's necessary for to make continuous efforts to explore how to cultivate the innovation spirit of grey collar talents, increase the proportion of grey collar talents in the labor force, improve the structure of grey collar talents as well as the obsolete mechanism, enhance the assessment mechanism of grey collar talents and promote grey collar talents to develop faster and better.

\section{References}

[1] Y.M. Sun, "Professorship education - Cradle of "the dust gets talents"," China Science and Technology Information, vol. 17, pp. 152, September 2005.

[2] H.W. Liu, "The allocation of high-skilled talent resources and vocational education," Reformation \& Strategy, vol. 2, pp. 161-163, June 2008.

[3] L. Wößmann, "Efficiency and equity of European education and training policies," International Tax and Public Finance, vol. 15, no. 2, pp. 199-230, April 2008.

[4] T. Korpi, P. de Graaf, J. Hendrickx and R. Layte, "Vocational training and career employment precariousness in Great Britain, the Netherlands and Sweden," Acta Sociologica, vol. 46, no. 1, pp. 17-30, March 2003.

[5] L.Z. Qiu, "A historic choice: the Ningbo module of vocational higher education for serving the community and society," US-China Education Review, vol. 4, no. 26, pp. 20-24, January 2007.

[6] C. McInnis, R. Hartley, J. Polesel and R. Teese, "Non-completion in vocational education and training and higher education," Australian Capital Territory: Canberra, 2000.

[7] Z.J. Duan, "The construction of the talents' training pattern of higher vocational education taking employment as the value orientation," Vocational and Technical Education, vol.28, pp. 33-35, December 2004.

[8] J.P. Liu, L.F. Qiu, D.Y. Li, Q.W. He and Y.C. Zhang, "Exploration \& Practice of higher vocational talent developing mode based on embedded construction," Journal of hunan industry polytechnic, vol. 10, no. 5, pp. 94-97, January 2010.

[9] Z.Y. Zhang and S. Liu, "The enlightenments from comparing the twoprinciple parts training mode and the order training mode," Journal of Jinzhong University, vol. 5, pp. 79-82, November 2006.

[10] A. Eck, "Job-related education and training: their impact on earnings," Monthly Labor Review, vol. 116, no. 10, pp. 21-38, October 1993. 